\title{
Acumulação fictícia, especulação e instabilidade financeira (Parte II: uma reflexão sobre a financeirização a partir da literatura contemporânea) *
}

\author{
Ricardo Carneiro ${ }^{* *}$
}

\begin{abstract}
Resumo
O objetivo deste texto é o de analisar interpretações contemporâneas sobre a financeirização visando construir uma abordagem particular sobre o tema, dando continuidade ao texto anterior Carneiro (2019), no qual se discutiu o assunto a partir da concepção de autores clássicos. A reflexão sobre a literatura contemporânea adotará como paradigma os princípios teóricos propostos por Marx, Keynes e Minsky aos quais se associam os conceitos de acumulação fictícia, especulação e instabilidade financeira. Com esta perspectiva, pretende-se não só estabelecer uma continuidade entre o ensaio anterior e o atual, mas também, examinar a literatura à luz de um ponto de vista teórico definido, objetivando construir alguns princípios analíticos para compreender a financeirização contemporânea. A abordagem considerará os elementos mais gerais característicos desta etapa, como a acumulação fictícia ou especulativa, como eles se manifestam no plano dos agentes econômicos - intermediários financeiros, empresas e famílias - e como estes últimos reforçam as características gerais desta fase do desenvolvimento capitalista.
\end{abstract}

Palavras-chave: Financeirização, Ciclo financeiro, Bolha, Maximização do valor acionário, Securitização complexa, Shadow banking, Polarização social.

\begin{abstract}
Fictitious accumulation, speculation and financial instability (Part II: An analysis of financialization based on the contemporary literature)

The aim of this text is to analyze contemporary interpretations of financialization in order to create a particular approach to the subject, continuing on from the previous text, Carneiro (2019), in which the conceptions of classical authors were discussed. The discussion on contemporary literature will adopt as a paradigm the theoretical principles proposed by Marx, Keynes and Minsky, associated with the concepts of fictitious accumulation, speculation and financial instability. Through this perspective, it is intended to not only establish continuity between the previous and the present essay, but also to examine the literature in light of an established theoretical point of view, in order to build analytical principles to understand contemporary financialization. The approach will consider the more general elements characteristic of this stage, such as fictitious or speculative accumulation, as they manifest at the level of economic agents - financial intermediaries, companies and families - and how these agents reinforce the general characteristics of this phase of capitalist development.
\end{abstract}

Keywords: Financialization, Financial cycle, Bubble, Maximizing share value, Complex securitization, Shadow banking, Social polarization.

JEL B50, G01, G10, P12, P16.

\footnotetext{
* Artigo recebido em 11 de novembro de 2019 e aprovado em 4 de março de 2020.

${ }^{* *}$ Professor Titular do Instituto de Economia da Universidade Estadual de Campinas (IE. Unicamp), Campinas, SP, Brasil. E-mail: carneiro@unicamp.br. ORCID: http://orcid.org/0000-0001-6623-684X.
} 


\section{Introdução}

A financeirização tem sido tratada na literatura como um tema bastante amplo, abrangendo não somente aspectos econômicos, mas sociais, políticos e até culturais, como fica evidente nas resenhas mais completas realizadas sobre o tema por Van der Zwan (2014), Lapavitsas (2011), e Palludeto e Felipini (2019). O objetivo deste texto, todavia, é bem menos ambicioso e objetiva circunscrever sua reflexão à esfera da economia política, dando continuidade ao texto anterior Carneiro (2019), no qual se analisou a financeirização a partir da concepção de autores clássicos. Como continuidade desta reflexão, pretende-se incursionar pelas interpretações contemporâneas, com o objetivo de identificar elementos analíticos que possam constituir-se em uma abordagem própria da financeirização.

Assim, a reflexão sobre a literatura contemporânea adotará como paradigma os princípios teóricos propostos em Carneiro (2019), onde se ressaltava três autores seminais, Marx. Keynes e Minsky e aos quais se associava os conceitos de acumulação fíctícia, especulação e fragilidade financeira. Com esta perspectiva pretende-se não só estabelecer uma continuidade entre os dois ensaios, mas também examinar a literatura contemporânea à luz de um ponto de vista teórico definido e delas extrair alguns princípios analíticos. A abordagem considerará os elementos mais gerais característicos desta etapa, e como eles se manifestam no plano dos agentes econômicos - intermediários financeiros, empresas e famílias- e como estes últimos reforçam as características gerais desta fase do desenvolvimento capitalista.

Por fim, uma ressalva se faz importante. A despeito da financeirização enquanto etapa de desenvolvimento capitalista ter uma dimensão internacional decisiva, por meio da globalização financeira e da globalização produtiva, elas não serão objeto de análise neste texto. As mudanças no sistema monetário e financeiro internacional com uma hierarquia monetária mais rígida e com mudanças na natureza e determinantes dos fluxos de capitais, bem como a nova divisão do trabalho fundada nas cadeias globais de valor, são temas abrangentes e correlatos, que podem ser tratados per se, sem prejuízo da abordagem aqui proposta.

\section{Financeirização: aspectos gerais}

Uma primeira pergunta que perpassa toda a literatura é a de como caracterizar a financeirização? Possivelmente, a tentativa de caracterização mais abrangente - mas, não necessariamente mais precisa - da financeirização é feita pelos regulacionistas, como por exemplo, nos textos de Boyer (2000), Aglietta (2000) e Aglietta e Rebérioux (2005), nos quais o objetivo é discutir se o regime que denominam de finance led poderia substituir aquele do regime regulado de Bretton Woods, que teve como fundamento a relação salarial (wage led). Assim, no padrão finance-led, o sistema financeiro impõe as normas gerais para o funcionamento da economia que seriam apropriadas no nível da firma pela nova governança centrada no primado do acionista, com importantes implicações tanto na relação intercapitalista, via padrão de concorrência das firmas, e natureza do investimento, quanto nas relações de trabalho, internas às firmas ou salariais, e externas, relativas à seguridade social. 
De uma perspectiva marxista, mas correlata, autores como Chesnais (2005) contribuem para detalhar o modelo regulacionista e identificam na dominância financeira duas características básicas: a centralização das poupanças financeiras de famílias e empresas, por meio dos investidores institucionais, e a modificação do padrão de governança das empresas, propondo as finanças como esfera dominante. No âmbito da centralização das poupanças e de seu controle pelos grandes gestores de portfólio, considera-se uma série de mudanças correlatas no funcionamento dos mercados financeiros, tais como a retomada da finança direta (securitização), a crescente liquidez dos mercados secundários, e por último, mas não menos relevante, a desregulação desses mercados. Essas transformações significaram, para o mercado de títulos de propriedade (ações), o estabelecimento de uma norma de rentabilidade e liquidez que induziu às mudanças na governança corporativa. Ou seja, reafirma-se a tese de que a dinâmica dos mercados financeiros constituiu uma norma de desempenho, que se impõe ao mundo produtivo.

Analisando este padrão, Aglietta e Valla (2017), destacam também a hegemonia da esfera financeira e sua preeminência na determinação da sua dinâmica e na eclosão das crises. Todavia, alertam para o fato de a esfera real constituir um critério de última instância para validar o ocorrido na primeira. Mostram ademais, que o decisivo são as decisões atinentes à valorização patrimonial. Todos os agentes, sem exceção, estão prioritariamente preocupados em ampliar a sua riqueza, nas mais variadas formas, sobretudo a financeira, através dos ganhos de capital, e buscam financiar essa ampliação da maneira mais adequada e, com alavancagem crescente. As crises decorrem de uma insustentável valorização dos ativos, acompanhada da deterioração das condições de financiamento.

$\mathrm{Na}$ discussão dos mecanismos de transmissão, vale dizer, das relações entre acumulação financeira e produtiva, a contribuição de Aglietta e Valla (2017), é muito esclarecedora. Para eles, a questão essencial é o atrelamento do ciclo econômico tradicional ao ciclo de preços dos ativos, esse último intimamente dependente da expansão do crédito direcionado à especulação. Essa interação se daria por meio do gasto das famílias e empresas, que tem comportamento pró-cíclico ante a variação dos preços dos ativos.

Cabe enfatizar que do ponto de vista da dinâmica econômica, um dos pontos centrais da argumentação da corrente regulacionista-marxista é a da exterioridade e preeminência do padrão ou patamar de valorização estabelecida pelos mercados financeiros e sua transmissão às empresas, por meio de normas criadas e adotadas por esses mercados. Ou seja, os mecanismos de valorização fictícia são cruciais para a estruturação e dinâmica da economia financeirizada.

Um aspecto detalhado por Aglietta e Valla (2017), se refere ao caráter autorreferencial de valorização dos ativos financeiros e, portanto, da formação das bolhas. Partem de um conceito keynesiano clássico, o da especulação, e postulam a distinção entre valor fundamental - deduzido a partir dos rendimentos esperados e da taxa de juros esperada - e o valor especulativo construído a partir da expectativa de variação do preço do ativo, na sua compra e 
Ricardo Carneiro

venda nos mercados organizados, de forma relativamente independente das variáveis anteriores.

Esses autores defendem a tese de que há pelo menos duas razões pelas quais os valores dos títulos podem mudar nos mercados secundários independentemente dos fundamentos: uma variação do risco de crédito e modificações na aversão ao risco, estas últimas muito influenciadas pela liquidez do mercado. Ressaltam também que, dada a heterogeneidade dos agentes que participam dos mercados, com modelos e critérios de avaliação distintos, é praticamente impossível chegar-se a um valor fundamental consensual.

Assim, do ponto de vista hierárquico, os mercados financeiros e o valor dos ativos seriam as variáveis cruciais de determinação da dinâmica da economia financeirizada. Estes mercados se organizam de uma forma distinta dos mercados de bens e serviços na medida em que possuem uma lógica autorreferencial e mimética, que pode levar a uma demanda crescente diante de aumentos de preços dos ativos e vice-versa.

A partir da autonomia relativa, mimética e autorreferencial da formação dos preços dos ativos, Aglietta e Valla (2017) analisam o que denominam de preponderância do ciclo financeiro. Este último resultaria da interação entre variação de preços de ativos e endividamento, que determinariam os gastos dos agentes e o ciclo real. Na verdade, está subjacente a esta ideia a tese de que os fluxos (produção e renda) não são independentes dos estoques (portfólios financeiros), mas subordinados a eles.

O tema do ciclo financeiro está tratado também com grande pertinência por Borio (2014), que distingue o ciclo tradicional, que denomina de ciclo de negócios, do ciclo financeiro, cuja primazia e caráter determinante seria indiscutível. Assim, o ciclo financeiro possuiria como característica principal uma simultaneidade entre aumento do crédito e dos preços dos ativos e um efeito riqueza generalizado. A trajetória deste ciclo seria necessariamente de boom e burst, configurando um dinâmica na qual o primeiro causa o segundo, numa clara démarche minskyana.

A distinção assinalada por Borio (2014), entre o ciclo de negócios tradicional e o ciclo financeiro, é assim, crucial. Desde logo, porque o ciclo financeiro se refere a uma dinâmica de estoques, portanto de balanço, e o boom e o burst resultam dos comportamentos e desequilíbrio desta dimensão. Exatamente por dizer respeito à evolução dos estoques e seus ajustes e desajustes, o ciclo financeiro tem duração e intensidade muito maior do que o de negócios. Qualquer que seja a origem dos desequilíbrios; o excesso de capacidade produtiva, de endividamento ou uma bolha de preços de ativos, ele aparece como um desequilíbrio de balanço e uma inadequação dos fluxos aos estoques.

Assim, a tese essencial de Borio (2014), é a de que o boom que se expressa no superendividamento decorre da excessiva elasticidade do sistema de crédito e de sua poderosa inclinação pró-cíclica, exacerbadas pela desregulação. Desse ponto de vista, a utilização de colaterais como garantia dos créditos e o aumento de seus preços/valores é a prática que permite 
esta elasticidade e a ausência de percepção da fragilidade financeira. Flutuações das taxas de juros tem impacto pró-cíclico crucial, na medida em que alteram o valor dos ativos e dos colaterais. Sua subida promove um forte desequilíbrio entre ativos, passivos e valor das garantias (colaterais), cuja magnitude torna impraticável o ajuste via fluxos.

Analisando esta dinâmica de uma perspectiva marxista, Chesnais (2005) destaca que o regime encerraria duas contradições mais importantes, a primeira delas, relativa ao descompasso entre a acumulação produtiva e a financeira que se expressa empiricamente no crescimento da relação valor da riqueza financeira/PIB, o que significa que os direitos sobre a renda estão crescendo mais rápido do que a mesma. A segunda, um tanto polêmica, se refere à contradição ou relativa incompatibilidade entre o processo de valorização financeira no plano da firma, que exige liquidez, e a inovação tecnológica, que implica iliquidez e maior prazo de maturação.

Em resumo, a questão essencial não diz respeito apenas às formas de aquisição e financiamento da riqueza, vale dizer, à sua dinâmica patrimonial. Essas estruturas patrimoniais podem se revelar adequadas, do ponto de vista financeiro, enquanto a taxa de valorização dos ativos subjacentes exceder a taxa de juros à qual os agentes se financiam. Isto, porém, pode não satisfazer o critério de segunda ordem relativo às variáveis reais, produção ou renda. Por exemplo, a compra de ações por meio de empréstimos pode determinar uma operação lucrativa quando a valorização das ações for maior do que a taxa de juros. A sustentação dessa valorização, por sua vez, não é independente dos lucros efetivos dessa mesma ação, ou seja, ela não pode ser sustentada permanentemente em bases psicológicas. Dito de outra maneira, e recorrendo à abordagem de balanço minskyana, a longo prazo, são os fluxos de rendimentos das ações que devem ser utilizados para pagar os encargos financeiros dos financiamentos utilizados para a sua compra.

No trabalho de Van Treeck (2009), há uma tentativa de discutir a consistência macroeconômica de alguns conceitos da financeirização, sobretudo àqueles que atribuem preeminência à esfera financeira e aos lucros dela derivados. Na verdade, o autor faz uma crítica à teoria da financeirização, mostrando sua suposta inconsistência macroeconômica quando ela propõe que a queda dos investimentos em ativos instrumentais, e a correspondente redução dos lucros agregados, são inconsistentes com o aumento dos lucros com origem financeira.

Há uma dupla problemática na discussão acima e que o autor não considera. Em primeiro lugar, é correto afirmar que os gastos, e particularmente os investimentos, determinam os lucros agregados. Como consequência, se os investimentos caem os lucros também o fazem. Contudo, como reconhece o autor, os lucros agregados podem aumentar por conta de outros gastos autônomos como o déficit público, as exportações, ou mais importante para economias de grande porte, o consumo financiado a crédito. Porém, mesmo que os gastos autônomos não aumentem, é possível haver uma redistribuição distinta das partes alíquotas do lucro. Se forem, por exemplo para os dividendos, isto permitiria um aumento dos preços das ações e, portanto, 
um lucro fictício, representado pelo ganho de preços que obviamente só pode se realizar se houver compradores para estas ações. É aí que entra o conceito de ganho ou capital fictício alimentado a crédito, que é independente dos lucros agregados. A partir da valorização inicial das ações fundadas na redistribuição dos lucros, pode haver a formação de uma bolha de preços alimentada pelo crédito. E isto aparece como um aumento da riqueza e, portanto, da valorização da riqueza financeira sem conexão imediata com os lucros agregados.

Uma discussão importante derivada da anterior é a do menor dinamismo da acumulação produtiva no regime financeirizado, proposta por Stockhammer (2004). Na verdade, a sua discussão centra-se no uso alternativo do lucro e, portanto, da poupança. Assim, em princípio, o uso alternativo entre ativos instrumentais ou financeiros, ou seja, o uso do funding para uma ou outra alocação, pode ter implicações sobre o ritmo de acumulação. Na aquisição de ativos instrumentais, a parte desviada para compra de ativos financeiros pode ser substituída por crédito (finance) no financiamento dos ativos instrumentais, portanto, com ampliação da alavancagem. Na prática, pode-se manter ritmo de acumulação semelhante com usos distintos do funding, desde que substituído pelo finance, mas com aumento da fragilidade financeira. Esta discussão, como a das restrições ao progresso técnico, será retomada à frente, ao se analisar a escolha entre diversas classes de ativos no contexto da nova governança das firmas.

\section{A financeirização dos intermediários financeiros}

As mudanças nos intermediários financeiros - bancos e não bancos - constituem a expressão maior da financeirização. De um lado, porque centralizam as grandes massas de riqueza financeira que são o elemento crucial da dinâmica econômica por meio de seus processos autônomos de valorização e de transmissão à economia real. De outro, porque dão elasticidade ao processo, via crédito.

Os investidores institucionais e, em particular os fundos de investimento de vários tipos, constituem-se como atores estratégicos do capitalismo financeirizado contemporâneo. Autores como Farnetti (1998) os julgam como essenciais em razão das elevadas e crescentes massas de riqueza financeira que administram, bem como do acesso privilegiado ao crédito, pois tornam-se o locus por excelência do processo de controle, centralização e valorização fictícia do capital. A sua ação condiciona a direção e intensidade do processo de acumulação financeira, ou seja, a morfologia e intensidade dos processos de valorização fictícia. Na verdade, são eles que estabelecem os padrões de valorização do capital.

Conforme assinalado por Sauviat (2004), a relevância desses intermediários financeiros foi condicionada pela desregulação que permitiu a gestão dessa poupança por critérios de mercado, ao mesmo tempo em que essas massas de capital dinheiro cresceram desproporcionalmente, por conta da mercantilização da proteção social: aposentadorias, saúde, educação, vida, etc. Farnetti (1998) destaca também a proliferação dos fundos livres, voluntários ou mútuos em parte, substitutos dos depósitos à vista e a prazo nos bancos. Como 
pano de fundo, a crescente gestão terceirizada desses fundos, mesmo os de pensão, e a remuneração por critério de performance.

Nesse sistema, as poupanças de curto e longo prazo, ou seja, os fundos de diversa natureza, têm os seus objetivos crescentemente unificados em torno da obtenção de ganhos patrimoniais. Aqueles de longo prazo, cuja preocupação deveria ser com os rendimentos, por conta dos seus compromissos atuariais, passam a se pautar, pelo menos em parte, por resultados de curto prazo, e a perseguição de ganhos de capital, decorrente da imposição de critérios de performance (benchmarking). A concorrência e o mimetismo comandam esse padrão de operação dos fundos.

Para detalhar a proposição anterior cabe refletir sobre a família de fundos a partir da exigibilidade de seus passivos, que vão desde o longo até o curtíssimo prazo. Assim, uma tipologia genérica que organize os fundos a partir das exigibilidades ou liquidez dos passivos, teria num extremo o fundo de pensão, e em sequência os fundos de seguro, vida, saúde e demais, os fundos mútuos, os hedge funds e os money-market funds. Mas, como apontado, esta hierarquia sofreu modificações ao longo do tempo na direção de aproximá-las.

De acordo com Farnetti (1998), toda a questão se cristaliza na redução das exigibilidades, e sua transformação pela lógica da performance. Na medida em que esta exigibilidade sobre o passivo diminui, a composição dos ativos também se modifica. Assim, o aprofundamento desse processo levou ao crescente curto-prazismo na gestão de toda a família de fundos. Os ingredientes desta modificação são: o caráter autorreferencial da valorização, descolado de qualquer critério objetivo, a crescente concorrência permitida pela desregulação e a progressiva liquefação dos ativos estribadas em mercados secundários cada vez mais amplos. Como pano de fundo dessas características e o caráter crescentemente fictício da valorização, se põe a prática de "marcação a mercado", a conferir elasticidade ao processo.

Um aspecto importante se refere ao caráter fictício ou especulativo da valorização dos ativos desses fundos. Ou seja, o rendimento acima da remuneração contratual dos papéis ou dos dividendos capitalizados, só pode ser explicado pelas operações alavancadas de algumas famílias de fundos, vale dizer, o acesso ao crédito e sua utilização na formação das carteiras. Os atores privilegiados deste processo são os hedge funds.

Dentro da lógica geral de centralização das poupanças financeiras e a constituição de unidades mais ativas na determinação e busca de rendimentos, via investidores institucionais, autores como Coffee Jr. e Palia (2015) destacam a atuação dos hedge funds. Aqui, trata-se de caracterizar Investidores Institucionais cujas práticas vão além do estabelecimento genérico de normas para o retorno das atividades produtivas. Desta forma, os hedge funds seriam uma espécie de vanguarda da financeirização dos fundos. Na verdade, estes últimos representam uma forma superior ou avançada de articulação dos interesses dos poupadores e dos acionistas, em particular. Algumas características definem melhor os hedge funds vis a vis os demais: administração das poupanças baseadas estritamente em critérios de performance; número 
restrito de investidores; participação expressiva, não atomizada em empresas; operação nos limites da legislação, forçando a sua mudança.

Os autores vinculam claramente a ação dos hedge funds que denominam de investidores ativistas às grandes modificações ocorridas na governança corporativa, conduzindo à crescente alavancagem, ampliação de pagamento de acionistas (via dividendos e buybacks) e redução dos investimentos instrumentais, sobretudo os baseados em P\&D. Isto decorreria em boa medida da ação dos hedge funds sobre as empresas, como detalhado adiante. Como estes últimos definem normas de remuneração elevadas e a serem obtidas sistematicamente, e não é possível consegui-la operando normalmente, eles adotam como prática o ativismo que induz as empresas nas quais tem participação a um comportamento orientado para os resultados fictícios e de curto prazo.

Outro ator crucial das economias capitalistas e que sofreu importantes modificações durante a financeirização foram os bancos. O trabalho de Hardie e Howarth (2013) propõe que a financeirização eliminou as diferenças institucionais existentes entre os sistemas financeiros, como a distinção bank based x capital market based, tendo o sistema convergido para o marketbased banking. A partir daí, os bancos se mantiveram como agentes centrais do financiamento, negando as teses da prevalência da desintermediação do sistema financeiro. Na verdade, como ressaltado por Turner (2010), os bancos se utilizaram extensivamente do que denomina de securitização complexa.

No período pré-financeirização, os ativos dos bancos eram compostos em grande medida, por empréstimos e suas obrigações, por depósitos. Os movimentos de curto prazo das cotações dos mercados pouco influenciavam o valor de ativos e passivos. Esta situação mudou radicalmente com a "mercadização" de ambos, ativos e passivos, e com os bancos incorporando as atividades de investimento, shadow banking e derivativos. Autores como Aglietta e Valla (2017), destacam que os bancos enfrentaram grandes desafios nos anos 1980, com a perda de bons clientes para as finanças diretas e a elevação dos custos de captação devido ao surgimento de alternativas aos depósitos a vista, para os depositantes (money markets e now accounts) que rendiam juros. Foi esta pressão concorrencial e o ambiente de crescente desregulação que impeliu os bancos às transformações.

No que tange aos passivos bancários, estes deixaram de ser quase cativos e com custo nulo como eram os depósitos à vista e passaram a se originar em parcela expressiva, dos mercados, vale dizer, outros bancos, fundos e investidores em geral. $\mathrm{O}$ peso dos passivos não constituídos por depósitos, denominados de "funding gap" mostrou-se crescente. Os ativos, por sua vez, adquiriram como característica primordial a liquidez via securitização ou a transferência de risco, via derivativos. De um lado, isto ocasionou que os bancos mudassem a sua precificação dos empréstimos que passaram a refletir as condições dos seus mercados secundários, com implicações significativas sobre sua rentabilidade. Esta é uma modificação essencial da atividade bancária cuja determinação dos juros não se dá mais pela regra do spread. De outro, a liquidez dos ativos ocasionou a sua "marcação a mercado", ampliando o 
risco dos bancos, consideravelmente. Nos bancos em geral, mas sobretudo nos bancos de investimento, ganharam relevo as operações de proprietary trading, aquelas nas quais se utiliza o capital ou passivos captados no mercado para adquirir posições em diversos instrumentos financeiros, em detrimento das operações de intermediação financeira.

Autores como Turner (2010) vão na mesma direção e identificam três principais aspectos na transformação do sistema bancário: a inovação radical por meio da securitização e uso extensivo de derivativos, aumento da liquidez e, como produto dessas mudanças e exacerbando-as, o aumento da alavancagem. A inovação radical cria a securitização complexa, intermediada pelos bancos e que se distingue da securitização convencional, não intermediada, caracterizada pelo single-name $x$ single name. Assim, a securitização complexa engloba as práticas de pooling e tranching dos riscos, separando de forma radical as eventuais vinculações entre passivos e ativos bancários e exacerbando, portanto, as principais características do sistema bancário que é a transformação de maturidade e a desconexão de riscos.

Na prática, a securitização complexa ampliou os riscos do sistema bancário, por duas vias principais: o aumento do trading ou turnover dos principais instrumentos financeiros $\mathrm{e}$ maior liquefação dos ativos e passivos. O primeiro aspecto, se refere à ampliação dos empréstimos interfinanceiros, inclusive no interbancário que tornou o sistema mais independente da base de reservas do Banco Central, ampliando a disposição dos bancos a se autoconcederem crédito, às custas do aumento do risco sistêmico. O segundo, por meio da securitização, permitiu via arbitragem regulatória e ampliação do shadow banking, o aumento da alavancagem. Os riscos de ativos e passivos crescentemente liquefeitos e "marcados a mercado" foram enfrentados pelo uso extensivo dos derivativos.

Todas essas mudanças produziram uma transformação crucial na operação dos bancos: do financiar e reter (finance and holding) para originar e distribuir (originate and distribute), configurando a securitização complexa. Do ponto de vista geral, os bancos passam a recorrer de maneira sistemática aos derivativos como forma de reduzir os vários tipos de descasamento entre ativos e passivos, sobretudo aqueles que envolvem taxas de juros e o currency mismatch. Do ponto de vista dos ativos, dois instrumentos merecem uma consideração especial por conta da sua importância: o credit default swap (CDS) e a asset backed securities (ABS).

O CDS é usado quando o banco decide manter o empréstimo, e por isso decide mitigar o risco por meio da venda do risco do default, ou seja, não perde capital, apenas parte da rentabilidade e quando ocorre o default está garantido. O mecanismo de transferência de risco por este instrumento envolve um comprador de proteção/vendedor de risco, no caso o banco, e um vendedor de proteção/comprador de risco. Como não há transferência do empréstimo original, somente um evento de crédito gera um fluxo de pagamento.

As ABS, das quais a securitização de hipotecas imobiliárias são parte, tiveram um papel mais importante na crise subprime americana. Elas representam a securitização de empréstimos e sua venda ao mercado, utilizando-se frequentemente de veículos especiais fora do balanço - que fazem parte do shadow banking system. Esses veículos recombinam e 
reclassificam essas ABS e financiam as suas tranches nos mercados mais curtos como o de commercial paper. Isto permite tanto aumentar a alavancagem, pois a rigor esta é uma operação fora de balanço, quanto ampliar a rentabilidade, dado o menor custo das linhas de curto prazo. Mas, a transformação de prazos é levada ao paroxismo.

Esse conjunto de modificações não só ampliam o papel dos bancos na economia - em associação com variadas formas de instituições e instrumentos financeiros que compõem o shadow banking - e no ciclo financeiro, como aumentam o seu risco e o risco sistêmico. A dependência de uma base de captação de mercado sujeita o banco mais fortemente às flutuações da preferência pela liquidez e as consequentes flutuações das taxas de juros - descasando custos de ativos e passivos. No limite, os problemas de liquidez podem se agudizar com o travamento (credit crunch) dos mercados atacadistas, sobretudo do interbancário. Nos ativos, as possibilidades de stress também se ampliam, desde logo por conta da queda da qualidade dos financiamentos implícita na prática de originate and distribute. Há também a questão da marcação a mercado e dos possíveis desequilíbrios do passivo líquido daí advindos. Os problemas de liquidez também podem ser intensificados se as dificuldades do shadow banking impuserem uma reintermediação das ABS.

Autores de postura mais ortodoxa, como Buiter (2007), reafirmam que a excessiva securitização e os instrumentos das finanças estruturadas implicaram alguns problemas cruciais: a destruição de informações em razão do banco originador não ser a instituição que realiza a securitização; a opacidade decorrente do pooling pois, não se sabe exatamente quais são os ativos subjacentes aos títulos. Neste contexto, é importante também o papel negativo jogado pelas agências de classificação de risco. Na verdade, as agências sabem muito pouco e classificam os títulos com base em modelos (mark to model) em razão da opacidade das securities - o único risco considerado era o de default deixando de lado o de preço e o de liquidez - há conflito de interesses pois são pagas pelos emissores para classificar títulos e ainda trabalham para eles em outros serviços e, ainda mais, dada a opacidade dos produtos em geral, operam em parceria com os emissores.

A combinação entre securitização extensiva e complexa, as inovações financeiras da finança estruturada e o sistema bancário sombra (shadow banking system) tem uma alta capacidade de inflar bolha de preços de ativos e ampliar a fragilidade financeira. Na avaliação de Buiter (2007), como resultado desse processo chegou-se a dois problemas cruciais: a excessiva e pró-cíclica alavancagem, e a desintermediação excessiva com uma multiplicidade de instituições financeiras carregando títulos e financiando-os a curto prazo (muitas delas a serviço dos bancos para contornar restrições regulatórias). Isto levou ao somatório de instrumentos opacos com instituições opacas. A consequência foi a crescente fragilidade financeira.

\section{A financeirização das firmas}

Ao analisar a nova governança das empresas, Aglietta e Valla (2017) retomam uma proposição original dos regulacionistas para os quais as normas de rentabilidade são impostas 
pelos mercados financeiros às empresas. A forma destas cumprirem estas normas é adotar uma nova forma de organização que permita ampliar tanto o lucro corrente quanto a valorização patrimonial, independentemente do investimento produtivo. Por isto, terminam mudando de maneira radical a sua forma de organização e operação, convertendo-se, no limite, numa coleção de ativos negociáveis.

A partir da definição dos parâmetros externos para organização e desempenho das empresas pelo mercado financeiro, a literatura discute quais esses parâmetros. Os autores regulacionistas sugerem que o mercado financeiro, na verdade os controladores, exigem um lucro adicional das empresas por cima do lucro normal. Toda a questão se resume, portanto, em explicar a sua origem, partindo do pressuposto que se constituem como práticas que ampliam o lucro "fictício" no sentido de insustentável. A partir da ampliação da distribuição de dividendos, o aumento do preço das ações gera um processo especulativo de recompra das mesmas por parte da firma - com parte dos lucros ou empréstimos - aumentando o retorno total.

O tema do padrão de concorrência imposto pela nova governança e do lucro acima do normal é tratado por Nolan (2003), segundo o qual, no plano produtivo, ela implica a intensificação do regime de subcontratação e re-divisão dos lucros da cadeia de valor com a sua concentração na empresa controladora do core formando uma rígida hierarquia das taxas de lucro. Para ele, o core é um mecanismo de coordenação sobre uma ampla rede de fornecedores e revendedores que define em detalhe as especificações para a produção de partes e peças, desde locais de produção até gastos com P\&D. Em resumo, nessa nova forma de governança, o comando do core permite potenciar o controle sobre os processos produtivos para além daquele decorrente da concentração da propriedade.

Em outro trabalho, Nolan, Zhang e Liu (2007) mostram como no início do século XXI ocorreu uma significativa onda de concentração da propriedade das firmas por meio das F\&As. De maneira decisiva, o padrão dessas F\&As privilegiou a especialização com aquisição dos core business e não a conglomeração. A forma de organização também muda decisivamente em substituição ao sistema multidivisional. Assim, o sistema de integração é constituído por um core e um sistema de firmas externas.

A fonte de lucro adicional seria originária da reestruturação das empresas; de um lado da redução do peso dos salários pelo downsizing, de outro pela queda da relação K/P decorrente da especialização no core business (economia de capital) e por fim, pela captura dos lucros (quase rendas) dos fornecedores nas cadeias produtivas. $\mathrm{Na}$ verdade, haveria três razões substantivas para a especialização no core business; o aumento de competição em preços, a redução do prazo do monopólio tecnológico e os requerimentos externos de maior rentabilidade e distribuição de dividendos. Ou seja, há uma mudança no padrão de concorrência que é importante explicitar para explicar como o lucro adicional advém desse novo padrão, mas é insuficiente para explicar a valorização fictícia. 
O trabalho de Galston e Kamarck (2015) sumariza um conjunto de pontos relevantes no que tange ao primado do acionista e suas implicações na governança, desempenho e valorização fictícia das firmas. Sintetizam essa governança no que denominam de curtoprazismo, configurado no uso prioritário dos lucros para distribuir dividendos e recomprar as ações da companhia, e defendem que ambos são feitos em detrimento do investimento instrumental. Involucrado nesse curto-prazismo também estaria uma profunda modificação da relação salarial. A consequência dessas modificações foi uma diminuição proporcional do investimento e, portanto, do crescimento da produtividade e uma piora na distribuição da renda.

Outro aspecto crucial da modificação da governança das empresas assinalado por Galston e Kamarck (2015) diz respeito às mudanças na remuneração dos gerentes com a substancial ampliação da parte não monetária, em particular as opções de ações. O efeito prático disto é alinhar os interesses dos gerentes com o dos acionistas pois a remuneração dos primeiros e os ganhos dos segundos, passam a depender do desempenho das ações, ou seja, dividendos e preços. Importante assinalar que há um amplo aparato regulatório que dá suporte a essas práticas. Desde 1991, nos Estados Unidos, a Securities Exchange Comission mudou a regra de exercício das opções recebidas pelos executivos, permitindo o seu exercício imediato - referendando o eventual ganho de curto prazo. Ademais, esses ganhos são tratados como ganhos de capital obtendo um tratamento tributário mais favorável do que os recebimentos de salários e ordenados.

Lazonick (2012), também destaca a convergência de interesses entre a gerência e os acionistas para a maximização do valor acionário. Isto porque a remuneração parcial dos executivos em opções de ações reforça o interesse em ampliar seu valor por meio dos buy backs e da distribuição de dividendos. As indicações são inclusive de que as operações de recompra são levadas muito além do necessário para evitar a diluição da composição acionária original, decorrente do exercício das opções. Ou seja, os interesses da alta gerência, remunerada com opções de ações, exacerba as operações de recompra e a maximização do valor acionário (MVA).

Autores como Coffee Jr. e Palia (2015), assinalam com parte da nova cultura empresarial e do primado do acionista, uma pressão externa consubstanciada na ação dos investidores ativistas. $\mathrm{Na}$ verdade, esta pressão externa constitui em si mesma a principal característica da financeirização, ou a norma de retorno estabelecida pelos mercados financeiros. Toda a questão se resume em pressionar a administração para produzir dividendos e buybacks, ou seja, ganhos fictícios ou especulativos em detrimento daqueles que poderiam advir dos fluxos de caixa dos investimentos. A pressão ativista se consubstancia, prioritariamente pelo ativismo dos hedge funds por meio das campanhas ou raids que tem como alvo determinadas empresas e que incluem diversos níveis de constrangimentos, desde os mais simples como mudanças na administração para alinhá-la com os objetivos de curto prazo, até a compra ou venda. 
Os estudos citados por Coffee Jr. e Palia (2015), sugerem que a estratégia desses agentes é claramente predadora, como por exemplo, quando compram uma empresa, exploram ao limite as possibilidades de seus produtos inovadores, mas descontinuam os investimentos em P\&D. A especialização no core business é outra importante estratégia. Estas ações foram permitidas, por mudanças legais e regulatórias importantes, sobretudo, porque tornaram os custos de contestação das ações da Administração das empresas muito mais baratas, vulnerabilizando-as. De outro lado, permitiram uma ação colusiva muito mais aberta e sem restrições por parte dos hedge funds, bem como mais liberdade no que tange ao decréscimo de volume e tempo de manutenção em carteira das ações adquiridas, requeridas para ter sucesso numa decisão do conselho de direção.

O tema mais controverso na discussão do curto-prazismo é o da redução do investimento instrumental, decorrente do aumento dos dividendos e buybacks. Isto porque as fontes de recursos para o investimento, i.e., os lucros retidos, poderiam ser substituídos por financiamentos. Isto é verdade, mas mesmo neste caso a recompra de ações concorre com o investimento instrumental. De certa maneira, há mais risco e resultados mais incertos no investimento instrumental do que no financeiro. A teoria ortodoxa que dá suporte ao primado do acionista implicitamente aceita a tese de que a sua prevalência tem implicações sobre o nível de investimento instrumental. Contudo, propõe que o nível pode cair, mas a eficiência e a produtividade aumentam. Ou seja, estar-se-ia eliminando o excesso de investimento, o desperdício e a ineficiência, típicas de um regime comandado pela Administração - a construção de pirâmides. Isto porque a ampliação dos buybacks e dos dividendos ocorreria a partir do caixa livre, uma vez realizados os investimentos que superassem o custo de capital ou que possuem um valor presente líquido.

A questão acima leva necessariamente à discussão sobre a decisão do investimento e o que constitui um investimento eficiente ou não. Uma importante contribuição ao tema é feita por Haldane e Davies (2011), para quem o curto prazismo é definido como a miopia do mercado, ou seja, sua incapacidade de avaliar ou enxergar corretamente o longo prazo. Para caracterizar esta miopia, eles usam dois exemplos distintos: o primeiro diz respeito ao cálculo do valor líquido presente (net presente value) de um investimento qualquer. Sua constatação é de que no ambiente financeirizado as taxas de desconto são excessivamente elevadas e, portanto, distorcidas, e isto é tão mais verdadeiro quanto maior o prazo do investimento. Como resultado, uma parcela expressiva dos investimentos apresentaria NPVs negativos, deixando de serem efetivados.

Ou seja, a miopia consiste em distorcer as taxas segundo os prazos dos investimentos, mais altas do que deveriam ser para prazos mais longos e mais baixas para prazos mais curtos. Este procedimento deixa de fora projetos de investimento que seriam viáveis caso as taxas utilizadas fossem as apropriadas. Outro exemplo interessante diz respeito ao encurtamento de prazos para o payback de um investimento qualquer, utilizando-se períodos muito mais curtos do que aqueles apropriados para as características físicas do investimento - inclusive sua depreciação. 
Já autores como Kliman e Williams (2014) contestam a tese de Lazonick (2012) - que postula explicitamente o declínio do investimento instrumental, a despeito das várias ondas de inovação nos EUA durante o período - com base na observação de que não houve contradição entre o aumento da distribuição de dividendos e a recompra de ações com o aumento de investimentos porque as empresas tiveram amplas possibilidades de ampliar o endividamento, ou seja, a alavancagem. Esta última, teria inclusive ganho elasticidade em razão da própria valorização das ações, permitindo elevar o debt, devido ao aumento do equity.

A tese falha em explicar um fenômeno crucial do período, reconhecido pelos próprios autores: a queda dos investimentos em ativos fixos. A argumentação apresentada por eles é que a razão principal da queda dos investimentos em ativos fixos foi a redução dos lucros e não o seu uso alternativo. Porém, segundo o seu próprio argumento, poder-se-ia pensar que a alavancagem supriria o gap de recursos para investimento sendo, portanto, a queda dos lucros, pouco relevante.

À luz das controvérsias, há que se formular uma hipótese alternativa: embora de fato não exista uma competição direta e imediata entre os recursos usados para a distribuição de dividendos e recompra de ações e os investimentos em ativos fixos, em razão da alavancagem, o fato é que este último se reduziu. Assim, a maneira de conciliar essas várias tendências é pensar que houve uma influência indireta da financeirização, ou da sua tradução no plano da firma, via maximização do valor acionário, sobre o investimento instrumental, mudando a sua intensidade e distribuição.

Diante de alternativas de ganhos patrimoniais, como a recompra de ações ou operações de F\&As, os investimentos em ativos instrumentais apresentariam desvantagens: a menor liquidez e, quando associado a inovações, o maior risco. Ademais, como mostram Aglietta e Valla (2017), utilizar a alavancagem tem limites e resulta da interação entre dois grupos com objetivos díspares: os acionistas que procuram a máxima alavancagem para processos de valorização que excedam a taxa de juros, e o emprestadores que racionam o financiamento a partir do princípio do risco crescente.

No que tange aos dividendos e buybacks, cabe considerar que eles refletem uma lógica patrimonial de valorização. No primeiro caso, tanto elevam o lucro por ação quanto permitem uma valorização das próprias ações, via capitalização. Já os buybacks representam um ganho patrimonial com implicações distintas. De uma perspectiva individual, as recompras implicam na sustentação ou elevação dos preços das ações, permitindo aos seus proprietários um ganho de valorização, caso o realizem. Esse mecanismo de recompra evita a diluição do preço das ações, quando do exercício de opções, recebidas em remuneração pelos gerentes. Ou seja, com o exercício das opções amplia-se o número de ações fazendo cair o seu valor unitário e com o buyback recompra-se, fazendo crescer o seu valor. Do ponto de vista da firma, usar lucros para recomprar ações, significa trocar lucro retido por um valor unitário mais alto das ações patrimônio líquido/número de ações - em razão da diminuição de seu número, ou seja, é como se o lucro fosse incorporado diretamente no valor das ações. 
O resumo de toda esta discussão pode ser colocado da forma a seguir, com o auxílio da abordagem de balanço. O primeiro aspecto se refere à composição dos passivos da empresa, ou como ela utiliza seus lucros retidos. A opção convencional prévia ao MVA era a de incorporar os lucros ao capital e assim financiar a expansão da firma com uma alavancagem (debt/equity), menor. A mudança principal introduzida pelo MVA é a distribuição ampliada de dividendos e o aumento dos buybacks de ações. Ambas terminam por ampliar a valorização das ações, principal interesse do acionista. Em contrapartida, a firma terá que financiar a sua expansão com mais dívida, ampliando a alavancagem.

Assim, a incorporação ou, alternativamente, a distribuição do lucro tem implicação sobre a forma como a firma financia a acumulação de ativos. Há aqui uma importante discussão acerca dos limites da alavancagem, ou se ela pode substituir a contento, de modo eficiente, o aumento do capital. O ponto a assinalar aqui é que a distribuição dos lucros amplia o capital (equity) de modo fictício - valorização patrimonial das ações - permitindo de fato maior alavancagem (debt/equity) às custas de maior fragilidade financeira.

Por sua vez, a escolha de ativos, se dá considerando as alternativas clássicas de rentabilidade, risco e liquidez. Do ponto de vista da rentabilidade, a melhor opção é a compra de um ativo instrumental que represente adição à capacidade produtiva, no mesmo padrão tecnológico, possibilitada pelo incremento da demanda. Aqui se deveria incluir também a alternativa de F\&As que representam ampliação de market share e ademais permitem também valorização patrimonial.

Se é verdade que o investimento em ativos instrumentais com as características apontadas acima é uma alternativa superior a outros investimentos, como por exemplo a de ativos financeiros que oferecem mais liquidez, mas menos rentabilidade, isto não é verdadeiro para o investimento em novos ativos instrumentais com um padrão tecnológico distinto. Isto porque envolvem mais risco, por conta de esforços de P\&D ampliados, muito menor liquidez e rentabilidade incerta. Desse ponto de vista, a escolha entre ativos novos e financeiros pode levar a uma maior escolha desses últimos nos quais as vantagens de rentabilidade e liquidez são maiores.

O ponto acima leva à discussão da natureza do progresso técnico e seus determinantes no capitalismo financeirizado. O trabalho de Serfati (2008) avança na análise do tema ao destacar a importância crescente dos ativos intangíveis na firma comandada pela lógica financeira. $\mathrm{Na}$ verdade, os ativos intangíveis são aqueles por meio dos quais se exerce o controle da firma sobre a cadeia produtiva. Ele se assenta em alguns monopólios particulares como o da propriedade intelectual, das marcas, canais de comercialização, etc. Este monopólio é o que permite obter ou extrair rendas das cadeias produtivas e definir o valor (renda capitalizada) do ativo intangível. Propõe assim, uma tese que é bastante importante: o progresso técnico ou os gastos de $\mathrm{P} \& \mathrm{D}$ se concentram cada vez mais nas formas de garantir esses monopólios e não nas inovações genuínas. 
A partir da tese anterior, que sugere um amortecimento do progresso tecnológico, como explicar as ondas de inovação no âmbito do capitalismo financeirizado? Os trabalhos de Block (2008) e Mazzucato (2015), sugerem que o Estado teve um papel crescente e decisivo na geração e disseminação dessas ondas de inovação por meio da construção dos chamados horizontes tecnológicos, nas áreas de informática, biotecnologia e medicina. Ou seja, o conjunto de políticas envolvidas no financiamento da pesquisa e inovação constituem uma forma de construção da fronteira tecnológica que será apropriada pelas empresas privadas cujo investimento em P\&D concentra-se sobretudo na fase de adaptação. Ou seja, o custo e o risco da inovação são bancados, sobretudo pelo Estado.

Por fim, do ponto de vista macroeconômico, a MVA cria uma dinâmica minskyana muito específica. Ou seja, a valorização das ações por conta da distribuição de dividendos, tem dois aspectos: o primeiro, é a transferência de lucros retidos para o acionista, cujo impacto macroeconômico é incerto, mas provavelmente contracionista se supusermos que os lucros retidos iriam tornar-se investimento e os dividendos apenas parcialmente, se tornarão consumo. O outro aspecto, é a valorização fictícia das ações, ou seja, a capitalização dos dividendos ampliados, aumentando o valor das ações e, portanto, a riqueza dos acionistas, podendo induzir via efeito riqueza ampliação do consumo das camadas mais ricas da população.

A outra questão é a dos buybacks ou recompra de ações. Há duas opções básicas: se a recompra ocorre com um estoque dado de ações ou com o seu aumento, que resultaria, por exemplo, do exercício de opções por parte dos gerentes. Com o número fixo de ações, a recompra aumenta seus preços ou, amplia e realiza a valorização fictícia. Do ponto de vista macro, seus efeitos são os mesmos da distribuição ampliada dos dividendos - redução do investimento contra aumento incerto no consumo. Se o número de ações cresce, a recompra evita a queda de seus preços. O efeito macro é o mesmo. Em síntese, todas essas práticas indicam um aumento da alavancagem das firmas e uma redução do novo fluxo de caixa que resultaria do investimento adicional. Ou seja, uma ampliação da fragilidade financeira. Como contrapartida, uma ampliação da riqueza financeira dos acionistas com efeitos incertos no consumo.

\section{A financeirização das famílias}

As transformações no mundo do trabalho e inserção das famílias no capitalismo financeirizado são muito amplas, compreendendo em sentido lato, as mudanças no emprego, na remuneração e suas formas e, na proteção social, por meio da mercantilização da saúde, previdência, educação, etc. Desse ponto de vista, a insegurança, a precarização e o cálculo financeiro perpassam o sistema de vida de grande parte das famílias.

Autores como Davis (2009) e Erturk et al. (2007) ao discutirem a questão social se referem a dois processos complementares para caracterizar a inserção das famílias no capitalismo financeirizado: a sociedade de proprietários (ownership society) e a democratização das finanças. O primeiro autor caracteriza o modelo ideal da ownership society 
como uma formação social na qual o trabalhador e, no limite, o cidadão, é substituído pelo proprietário, ou seja, a relação com o capital não é mais mediada pela empresa, mas se faz direto com os mercados financeiros. Dessa perspectiva, se distingue radicalmente do capitalismo do século XX, sobretudo o da sua segunda metade, no qual a grande corporação e suas relações com os trabalhadores constituía o núcleo do sistema, associada no caso europeu à presença do welfare state.

No capitalismo regulado, com destaque para aquele dos EUA, as relações de trabalho e emprego centradas nas grandes empresas tinham como elementos característicos as carreiras, ou mercados de trabalho internos e o conjunto de benefícios relativos à proteção social e participação nos lucros, configurando uma relação de longo prazo. A mudanças que ocorrem neste padrão se devem a profundas transformações institucionais e tecnológicas dentre as quais a principal é a fragmentação ou desverticalização da produção, que conduziu à redução do trabalho assalariado e à precarização das relações de emprego.

Tomando como referência o capitalismo financeirizado americano, Davis (2009), $e$ Lanzonick (2012) mostram que a quebra de monopólios tecnológicos e o acirramento da concorrência ao aumentar os riscos das empresas, induz, nos segmentos mais qualificados, a substituição do assalariamento pelas participações. Por outro lado, a ampliação da desqualificação/simplificação do trabalho, em um conjunto expressivo de tarefas também ampliou a rotatividade e a substituição de força de trabalho mais antiga com formação tradicional, por aquela imbuída das novas capacidades associadas à Tecnologia da Informação. Além disso, no cômputo da queda da ocupação manufatureira, a globalização ou exportação de empregos também foram essenciais. Este processo é mais intenso no setor de serviços no qual a tecnologia da informação, aumenta as possibilidades e intensidade da transmissão de dados e informações e permite estruturar parte da atividade em bases impessoais.

Ao analisar a configuração do emprego que nasce dessas transformações Kalleberg (2011) destaca a sua polarização entre empregos de baixa e alta qualificação, com o quase desaparecimento dos empregos intermediários, principalmente no setor de serviços. Dois processos distintos marcam esta polarização: o downsizing e o outsourcing. O primeiro foi o responsável pelo declínio das ocupações intermediárias que haviam se constituído como a parte mais relevante do emprego assalariado no capitalismo do pós-Segunda guerra. O segundo diz respeito à já referida exportação de parcela dos empregos intermediários, tanto na manufatura quanto nos serviços.

Para além das diferenças de qualificação e treinamento dos vários grupos, determinados pela tecnologia, a autora aponta mudanças na organização do trabalho como fatores importantes da polarização. Assim, foi crucial a crescente diferenciação do poder de barganha evidenciado, por exemplo, na superação da organização sindical por ocupação (craft unionism), que enfraqueceu a capacidade de negociação de grupos de trabalhadores menos qualificados. Em contraposição, mecanismos cartoriais, como a licença ocupacional, reforçou o poder dos trabalhadores mais qualificados. 
A polarização também foi ampliada pelas estratégias das empresas: low-road versus high-road. As primeiras dirigem-se para o trabalhador de baixa qualificação e intensifica a precarização, flexibilização e substituibilidade, buscando uma espécie de trabalho just-in-time. Já as segundas privilegiam a organização independente do trabalho e a remuneração por performance ou participação. Forma-se assim um mercado de trabalho com características duais e crescentemente, sem a mediação das organizações coletivas nos processos de negociação.

Davis (2009) avalia que as modificações ocorridas nos benefícios concedidos pelas corporações têm um papel essencial na modificação das relações de trabalho e na financerização das famílias. A expressão das relações estáveis e duradouras era o fundo de pensão de benefício definido e a sua conversão em fundo de contribuição definida e com portabilidade, o modelo 401k constituiu uma mudança crucial. Além dessa modificação, a extinção ou redução significativa dos benefícios foram essenciais, sobretudo nos EUA, país no qual a proteção social era em grande parte responsabilidade das corporações.

A significativa redução da proteção social por parte das corporações, e em outros países, que não os EUA, o desmonte parcial do welfare state induziu os trabalhadores a buscar amparo em outras fontes, ou seja, na acumulação de ativos, principalmente ações e imóveis. Isto corresponde não só à manutenção dos fundos de pensão do modelo $401 \mathrm{k}$ como também à ampliação da participação nos fundos de investimento (mutual funds), em detrimento da poupança bancária a taxas fixas. Essa mudança é crucial para a financerização das famílias na medida em que converte a sua poupança num valor "marcado a mercado". As inovações nos financiamentos das habitações e sua disseminação completam o quadro.

São todas essas mudanças que dão origem à ideia da sociedade de proprietários (ownership society) e, particularmente, à tese da democratização das finanças, entendida como o acesso crescente das famílias aos mercados de capitais e o gerenciamento eficaz deste acesso. Segundo Erturk et al. (2007), para as famílias que de fato acessam os mercados de capitais e são obrigadas a gerenciar seus patrimônios, os percalços e desvalorizações desses últimos nos anos 2000 deu alento à tese de que a solução para a prosperidade pessoal suporia a educação financeira. A tese chega a ser patética diante da crescente volatilidade, complexidade e opacidade dos ativos financeiros. A esse respeito, os surveys periódicos do Fed (Survey of Household Economics and Decisionmaking) mostram que cerca de $60 \%$ das pessoas adultas que possuem alguma forma de poupança para aposentadoria - exclusive os fundos de pensão de benefício definido - revelam pouco ou nenhum conforto em gerenciar essas poupanças. Ademais, mesmo a poupança para a aposentadoria não é universal, deixando de fora cerca de $25 \%$ da população adulta e mais de $40 \%$, quando se trata da metade da população de renda mais baixa.

Todas essas transformações nas relações sociais tiveram impactos significativos na distribuição da renda e da riqueza conforme a detalhada análise de Piketty (2018). Assim, considerando a distribuição como resultante de duas formas distintas de remuneração, a relativa 
ao trabalho e a relativa a propriedade, conclui que no aumento da desigualdade, foi preponderantemente a reconcentração da renda do trabalho a principal responsável - que explicou 2/3 do aumento total - cabendo a parte menor - 1/3 do total - às rendas do capital. Essa conclusão, reflexo da metodologia adotada pelo autor dá, portanto, muito mais peso às modificações promovidas pela financeirização no mercado de trabalho, vis a vis aquelas ocorridas na propriedade.

O aparato conceitual utilizado pelo autor para explicar a reconcentração da renda é bastante convencional e descritivo. Sua ideia central é a de que a distribuição piorou porque se ampliou a diferença entre $\mathbf{r}$ (a taxa de remuneração do capital) e $\mathbf{g}$ (a taxa de crescimento da renda), aumentando a diferença entre as duas na expressão $r>g$. Por essa razão aumenta o peso da remuneração do capital na renda. Todavia, isto ocorre não por conta de uma elevação desta remuneração, mas porque houve uma desaceleração do crescimento da renda.

As variáveis anteriores são cruciais para definir uma relação-chave para a distribuição, a relação capital/renda ( $\beta$ ) que expressa de maneira mais ampla o peso de cada elemento na distribuição; o capital ou o estoque de propriedades, e a renda. Ou seja, nesse caso estão contrapostos o valor do estoque e a sua remuneração e o fluxo da renda e seu crescimento. Assim, define que $\beta$ dependerá de duas variáveis, o crescimento da renda $\mathbf{g}$, e a taxa de poupança s, relacionadas assim: $(\beta=\mathrm{s} / \mathrm{g})$. Dada uma taxa de poupança qualquer, a relação capital/renda será tão maior quanto menor for o crescimento da renda e maior a taxa de poupança e vice-versa. As explicações para o valor de cada uma dessas variáveis repousam em fatores tecnológicos e demográficos como nos modelos convencionais de crescimento.

A segunda variável relevante é a participação da remuneração do capital na renda nacional ou $\alpha$. Assim ( $\alpha=$ r. $\beta$ ). A despeito do autor considerar que houve alguma ampliação do retorno do capital a partir dos anos 1980, trata a maior parte dessas variações como cíclicas, insustentáveis e resultantes das bolhas. Conclui dessa forma que dos fatores explicativos para o aumento da participação do capital na renda, aquele relativo à remuneração do estoque foi menos relevante do que aquele que resultou de novos acréscimos, via fluxos adicionais de poupança, num contexto de declínio do crescimento da renda. Esta constatação leva a uma conclusão importante e aparentemente paradoxal: a distribuição funcional da renda se altera em favor do capital - ou, como ressalta o autor, em favor do passado ou das heranças - mas a reconcentração pessoal da renda se deve menos à concentração nas rendas do capital vis a vis o que ocorreu com as rendas do trabalho.

Um ponto polêmico da análise de Piketty (2018) diz respeito ao peso dos fluxos e estoques na conformação da relação capital renda, dado que valor do capital é o valor corrente, "marcado a mercado" e, portanto, incorpora a valorização fictícia. Assim, como ele próprio mostra com seus dados, a sua conclusão não parece ser válida para os EUA e Reino Unido, países nos quais a taxa de poupança foi muito mais baixa nas últimas décadas e onde ademais se observou uma revalorização significativa dos ativos. 
Outra conclusão que merece ser qualificada é a das razões da reconcentração da renda, atribuídas preponderantemente às rendas do trabalho. A despeito de reconhecer que a reconcentração da renda do capital desempenhou papel relevante, respondendo por $1 / 3$ do aumento da concentração, o seu peso teria sido subsidiário. E aqui os fatores mais permanentes foram, além do crescimento da relação capital/renda, o tratamento tributário dos ganhos de capital. Pouco peso é atribuído aos ciclos de valorização de ativos. Na verdade, conforme analisa ao autor os ganhos de capital vis a vis a renda de trabalho só seriam mais relevantes do que as rendas do trabalho no milésimo superior da distribuição.

A constatação anterior faz Piketty (2018) contrapor - utilizando principalmente o caso dos EUA - a sociedade dos rentistas e a sociedade dos superexecutivos, concluindo pela maior relevância da segunda como explicação da reconcentração da renda. A questão metodológica central é a consideração de um conjunto de rendas e remunerações 'por performance, como oriundas do trabalho e não do capital, ampliando a participação dos rendimentos, em especial dos muito elevados, atribuídos ao primeiro.

Uma dimensão muito importante subjacente ao comportamento das famílias, são aquelas que ocorreram no padrão de emprego e distribuição da renda que terminam por reduzir não só a massa salarial como a propensão a consumir. O tema foi tratado amplamente por Piketty (2018) que constatou tanto uma piora na distribuição funcional da renda quanto na distribuição pessoal. Nesse último caso, constata a estagnação das rendas das classes populares e médias como uma importante consequência do processo.

De acordo com Aglietta e Valla (2017), a financeirização também modifica o comportamento econômico das famílias dentre os quais aquele relativo aos determinantes do consumo. Ela põe em relevo o peso que adquire a riqueza financeira ou o patrimônio nessas decisões. De um ponto de vista estrutural, esse aumento do peso da riqueza diminui a taxa de poupança como proporção da renda, ampliando a parcela dedicada ao consumo. Por sua vez, nas flutuações cíclicas a variação do valor da riqueza exacerba a expansão ou contração do consumo.

Formalmente, os autores propõem a existência de uma relação constante (a) entre renda $(\mathrm{Y})$ e riqueza $(\mathrm{W})$. Assim, a = Y/W. Numa situação na qual o estoque de riqueza não se altera, a manutenção da relação constante implica em que a variação da poupança dependerá da variação da renda, ou seja, a variação da riqueza será proporcional à variação da renda: ( $\Delta \mathrm{W}=$ a $\Delta \mathrm{Y})$. Visto de outro ângulo; chamando a taxa de poupança corrente $(\mathrm{S} / \mathrm{Y})$ de (s) e o crescimento da renda de (g), e dada a relação desejada entre renda e riqueza (a), a taxa de poupança observada vai ser igual a: $s=($ a. g). Se por qualquer razão a taxa de riqueza desejada varia, também varia a taxa de poupança. Por sua vez, uma variação autônoma da riqueza, W, implicará uma menor necessidade de poupança para manter a relação constante.

A partir das relações explicitadas acima, os autores propõem que tanto a mudança de longo prazo no patrimônio das famílias - oriunda da estrutura etária da população - quanto variações cíclicas, decorrentes das bolhas de preços, alteram a poupança e o consumo. Assim, 
o ciclo de preços de ativos determina uma redução da poupança e ampliação autônoma do consumo, ou seja, um aumento mais que proporcional vis a vis a renda. Mas, o mesmo ocorre quando da retração de preços desses ativos pois a poupança aumenta mais rapidamente para recompor a riqueza e o consumo cai mais que proporcionalmente. Um mecanismo adicional de ampliação do consumo decorre da valorização dos ativos e da prática de realização de lucros (equity extraction), muito comum no refinanciamento de hipotecas quando os preços dos imóveis aumentam. Ou seja, o crédito pode potenciar bastante os movimentos descritos acima.

\section{Conclusões}

Do exame das interpretações contemporâneas sobre a financeirização, à luz de conceitos como a acumulação fictícia, a especulação e a instabilidade financeira, associados respectivamente, a Marx, Keynes e Minsky, pode-se inferir princípios relevantes para a compreensão da dinâmica do capitalismo financeirizado. Conforme destacado na Introdução, esses princípios dizem respeito não só ao processo mais geral relativo à dinâmica da acumulação, mas como ela se manifesta no plano dos principais agentes e é reforçada por eles. Vejamos a seguir, uma síntese dos achados desse texto no que tange ao assunto.

$\mathrm{Na}$ discussão da dominância financeira analisou-se em detalhe como o sistema financeiro impõe as normas gerais para o funcionamento da economia e estas são apropriadas no nível da firma pela nova governança centrada no primado do acionista, com importantes implicações tanto na relação intercapitalista, via padrão de concorrência das firmas, e natureza do investimento, quanto nas relações de trabalho, internas às firmas ou salariais, e externas, relativas à seguridade social.

Constatou-se que a acumulação fictícia se caracteriza por bolhas recorrentes que representam uma dissociação entre acumulação produtiva e acumulação financeira associadas à alta alavancagem dos agentes, ou seja, à compra de ativos por meio da criação de crédito. $\mathrm{O}$ descolamento entre valor de mercado e valor fundamental tem uma implicação essencial, mas que só se revelará quando do estouro da bolha pois, num primeiro momento, ele não tem importância dado o interesse na valorização do ativo subjacente. Quando a bolha desinfla, há uma readequação do valor dos ativos aos rendimentos que são capazes de gerar. Se o ativo foi adquirido com crédito, há um desequilíbrio patrimonial, se foi adquirido com recursos próprios, explicita-se uma perda de capital.

Viu-se que os intermediários financeiros - bancos e não bancos - constituíram os agentes privilegiados da financeirização. De um lado, porque centralizam as grandes massas de riqueza financeira que são o elemento crucial da dinâmica economia, por meio de seus processos autônomos de valorização e de transmissão a economia real. De outro, porque dão elasticidade ao sistema, via crédito. Um aspecto importante na atuação desses agentes se refere ao caráter fictício ou especulativo da valorização dos ativos dos investidores institucionais. Ou seja, o rendimento acima da remuneração contratual dos papéis ou dos dividendos capitalizados, só pode ser explicado pela operação alavancada de algumas famílias de fundos, 
vale dizer, o acesso ao crédito e sua utilização na formação das carteiras. É um processo de valorização fictícia, e insustentável de maneira permanente, que se transmite como norma aos demais agentes da economia, sobretudo empresas.

Os bancos tiveram um papel renovado e crucial na financeirização via inovação radical por meio da securitização complexa e uso extensivo de derivativos, aumento da liquidez e, como produto dessas mudanças e exacerbando-as, o aumento da alavancagem. A combinação entre securitização extensiva, as inovações financeiras da finança estruturada e o sistema bancário sombra (shadow banking system) tiveram uma alta capacidade de inflar bolha de preços de ativos e ampliar a fragilidade financeira. Como resultado desse processo chegou-se a dois problemas cruciais: a excessiva e pró-cíclica alavancagem, estimulada pela prática da marcação a mercado, e a desintermediação excessiva com uma multiplicidade de instituições financeiras carregando títulos e financiando-os a curto prazo (muitas delas a serviço dos bancos para contornar restrições regulatórias). A consequência foi a crescente fragilidade financeira.

No que tange às firmas, evidenciou-se que um dos aspectos mais significativos da financeirzação diz respeito à mudança ocorrida na sua governança por meio da introdução da maximização do valor acionário, decorrente em larga medida dos padrões, normas e disciplina impostos pelos mercados financeiros. Para satisfazer essas normas de valorização, as empresas são induzidas não só a ampliar, por meios particulares, os lucros correntes, mas sobretudo a valorização fictícia de maneira relativamente independente da atividade produtiva.

A ampliação do lucro corrente ocorre prioritariamente, por meio do recrudescimento de práticas oligopolistas, com a especialização no core business e o reforço da apropriação dos lucros na cadeia produtiva por vários mecanismos, inclusive um controle mais estrito da tecnologia, mercados, marcas, etc. Faz parte deste processo uma ampliação permanente e significativa dos processos de F\&As no core business conduzindo a concentração a níveis inéditos. A valorização fictícia, isto é, a que não depende de resultados correntes tem dois mecanismos principais, a distribuição de dividendos e a recompra de ações, ambas contribuindo para elevar de maneira sistemática a valorização das ações.

Como consequência, a financeirazação muda a operação das empresas em várias direções. Para viabilizar o padrão de valorização fictícia, as empresas racionam o investimento e ampliam a alavancagem, construindo uma crescente fragilidade financeira. Por sua vez, o progresso técnico é reorientado para privilegiar o controle das cadeias, das marcas, dos canais de comercialização, etc. Desse ponto de vista, o progresso técnico substantivo, a grande onda de inovação, passa a depender crescentemente da ação e financiamento do Estado.

Como foi assinalado, as transformações no mundo do trabalho e inserção das famílias no capitalismo financeirizado são muito amplas, compreendendo em sentido lato, as mudanças no emprego, na remuneração e suas formas e na proteção social por meio da mercantilização da política social, ou seja, da saúde, previdência, educação, etc. Desse ponto de vista, a insegurança, a precarização e o cálculo financeiro perpassam o sistema de vida de grande parte das famílias. 
Acumulação fictícia, especulação e instabilidade financeira (Parte II: uma reflexão sobre a financeirização...

$\mathrm{Na}$ configuração do emprego que nasce dessas transformações destaca-se a sua polarização entre empregos de baixa e alta qualificação, com o quase desaparecimento dos empregos intermediários, principalmente no setor de serviços. Dois processos distintos marcam esta polarização: o downsizing e o outsourcing. O primeiro foi o responsável pelo declínio das ocupações intermediárias que haviam se constituído como a parte mais relevante do emprego assalariado no capitalismo do pós-Segunda guerra. $\mathrm{O}$ segundo diz respeito à exportação de parcela dos empregos intermediários, tanto na manufatura quanto nos serviços. Ademais, mudanças na organização do trabalho formam fatores importantes da polarização. Assim, foi crucial a crescente diferenciação do poder de barganha evidenciado que enfraqueceu a capacidade de negociação de grupos de trabalhadores menos qualificados. De todo esse quadro resulta também uma significativa reconcentração da renda e da riqueza decorrente não somente da polarização do emprego, mas sobretudo do crescimento da remuneração das rendas da propriedade e das mudanças na sua tributação.

A significativa redução da proteção social por parte das corporações, e em outros países, pelo desmonte parcial do welfare state induziu os trabalhadores a buscar amparo em outras fontes, ou seja, na acumulação de ativos, principalmente ações e imóveis. Isto corresponde não só à manutenção dos fundos de pensão do modelo $401 \mathrm{k}$, como também à ampliação da participação nos fundos de investimento (mutual funds), em detrimento da poupança bancária a taxas fixas. Essa mudança é crucial para a financerização das famílias na medida em que converte a sua poupança num valor "marcado a mercado". As inovações nos financiamentos das habitações e sua disseminação completam o quadro.

A distribuição da renda teve uma piora sensível, por duas razões complementares cujo peso depende da abordagem metodológica empregada -: as transformações nos mercados de trabalho e nas formas, gestão e tributação da propriedade. Assim, ela resultou da combinação de dois fenômenos; a ampliação do peso do rentismo e da remuneração dos super executivos. Aqui o aumento da polarização também foi visível com a perda de importância das remunerações médias. A piora na distribuição da renda conferiram também maior relevância aos fatores autônomos, como o crédito, e patrimoniais na determinação do consumo, tornandoo menos dependente da renda e mais associados aos ciclos de liquidez e de preços dos ativos.

\section{Referências bibliográficas}

AGLIETTA, M. Shareholder value and corporate governance: some tricky questions. Economy and Society, v. 29, n. 1, p. 146-159, 2000.

AGLIETTA, M.; REBÉRIOUX, A. Corporate governance adrift: a critique of shareholder value. Edward Elgar Publishing, 2005.

AGLIETTA, M.; VALLA, N. Macroéconomie financière. 2017. (Collection: Grands Repères Manuels). 
Ricardo Carneiro

BLOCK, F. Swimming against the current: the rise of a hidden developmental state in the United States. Politics \& Society, v. 36, n. 2, p. 169-206, 2008.

BORIO, C. The financial cycle and macroeconomics: what have we learnt? Journal of Banking \& Finance, v. 45, p. 182-198, 2014.

BOYER, R. Is a finance-led growth regime a viable alternative to Fordism? A preliminary analysis. Economy and Society, v. 29, n. 1, p. 111-145, 2000.

BUITER, W. H. Lessons from the 2007 financial crisis. 2007.

CARNEIRO, R. Acumulação fictícia, especulação e instabilidade financeira. Parte I: uma reflexão sobre a financeirização a partir de Marx, Keynes e Minsky. Economia e Sociedade, v. 28, n. 2, p. 293-312, 2019.

CHESNAIS, F. A finança mundializada: raízes sociais e políticas, consequências. São Paulo: Boitempo, 2005. p. 17-33.

COFFEE JR, J. C.; PALIA, D. The wolf at the door: the impact of hedge fund activism on corporate governance. Annals of Corporate Governance, v. 1, n. 1, p. 1-94, 2016.

DAVIS, G. F. Managed by the markets: how finance re-shaped America. Oxford University Press, 2009.

ERTURK, I.; FROUD, J.; JOHAL, S.; LEAVER, A.; WILLIAMS, K. The democratization of finance? Promises, outcomes and conditions. Review of International Political Economy, 14, p. 553-575, 2007.

FARNETTI, R. O papel dos fundos de pensão e de investimentos coletivos anglo-saxônicos no desenvolvimento das finanças globalizadas. A mundialização financeira: gênese, custos e riscos. São Paulo: Xamã, 1998. p. 183-210.

GALSTON, William A.; KAMARCK, Elaine C. More builders and fewer traders: a growth strategy for the American economy. Center for Effective Public Management at Brookings, 2015.

HALDANE, A. G.; DAVIES, R. The short long. In: SOCIÉTÉ UNIVERSITAIRE EUROPÉENE DE RECHERCHES FINANCIÈRES COLLOQUIUM, 29, Brussels, 11 may 2011.

HARDIE, I.; HOWARTH, D. (Ed.). Market-based banking and the international financial crisis. Oxford University Press, 2013.

KALLEBERG, A. L. Good jobs, bad jobs: the rise of polarized and precarious employment systems in the United States, 1970s-2000s. Russell Sage Foundation, 2011.

KLIMAN, A.; WILLIAMS, S. D. Why 'financialisation' hasn't depressed US productive investment. Cambridge Journal of Economics, v. 39, n. 1, p. 67-92, 2014. 
LAPAVITSAS, C. Theorizing financialization. Work, Employment and Society, v. 25, n. 4, p. 611-626, 2011.

LAZONICK, W. The financialization of the US corporation: what has been lost, and how it can be regained. Seattle Ul Rev., 36, p. 857, 2012.

MAZZUCATO, M. The entrepreneurial state: debunking public vs. private sector myths. Anthem Press, 2015. v. 1.

NOLAN, P. Industrial policy in the early 21 st century: the challenge of the global business revolution. Rethinking Development Economics, 1, p. 299, 2003.

NOLAN, P.; ZHANG, J.; LIU, C. The global business revolution, the cascade effect, and the challenge for firms from developing countries. Cambridge Journal of Economics, v. 32, n. 1, p. 29-47, 2007.

PALlUDETO, A. W. A.; FELIPINI, A. R. Panorama da literatura sobre a financeirização (1992-2017): uma abordagem bibliométrica. Economia e Sociedade, v. 28, n. 2, 2019.

PIKETTY, T. Capital in the 21st century. In inequality in the 21st century. Routledge, 2018. p. 43-48.

PLIHON, D. 5. Les grandes entreprises fragilisées par la finance. In: LA FINANCE mondialisée. La Découverte, 2004. p. 125-145.

SAUVIAT, C. Os fundos de pensão e os fundos mútuos: principais atores da finança mundializada e do poder acionário. A finança mundializada. São Paulo: Boitempo, 2004

SEFARTI, C. Financial dimensions of transnational corporations, global value chain and technological innovation. Journal of Innovation Economics. v. 2, n. 2, 2008.

STOCKHAMMER, E. Financialisation and the slowdown of accumulation. Cambridge Journal of Economics, 28, p. 719-741, 2004.

TURNER, A. What do banks do? Why do credit booms and busts occur and what can public policy do about it. In: TURNER. A. et al. The Future of finance, 5, 2010.

VAN DER ZWAN, N. Making sense of financialization. Socio-Economic Review, v. 12, n. 1, p. 99-129, 2014.

VAN TREECK, T. The political economy debate on 'financialization' - a macroeconomic perspective'. Review of International Political Economy, 16, p. 907-944, 2009. 